\title{
Direct Numerical Simulations of Probe Effects in Low-Pressure Flame Sampling
}

\author{
Vyaas Gururajan, ${ }^{1}$ Fokion N. Egolfopoulos, ${ }^{1}$ Katharina Kohse-Höinghaus ${ }^{2}$ \\ ${ }^{1}$ Department of Aerospace and Mechanical Engineering \\ University of Southern California, Los Angeles, California 90089-1453, USA \\ ${ }^{2}$ Department of Chemistry \\ Bielefeld University, Universitätstrasse 25, D-33615 Bielefeld, Germany
}

\begin{abstract}
Speciation studies of low-pressure flames using intrusive sampling and molecular beam mass spectrometry analysis are essential towards developing and validating combustion models. In order to assess potential probe-induced effects, direct numerical simulations of a realistic experimental configuration were carried out using a finite-volume fully compressible code as well as detailed descriptions of chemical kinetics and molecular transport. A 50 mbar rich propene/oxygen/argon flame was modeled for which experimental data are available. The effects of the probe and supporting flange, non-adiabaticity, sampling location, and compressibility when there is suction through the sampling orifice were assessed. Results showed that even under adiabatic conditions, the presence of the probeflange assembly affects the flow field two-dimensionally. Furthermore, the effects of heat loss and compressibility were found to be significant at the sampling location. Important radicals for fuel oxidation such as $\mathrm{OH}$ and $\mathrm{HCO}$, and for soot formation such as $\mathrm{C}_{3} \mathrm{H}_{3}$ are affected by the sampling procedure and their concentrations at the sampling location can differ notably compared to unperturbed one-dimensional flames.
\end{abstract}

\section{Keywords:}

Low-Pressure Flames; Flame Sampling; Flame Structure; Flame Chemistry; Premixed Flames. 


\section{Introduction}

Data obtained in laminar flames are key towards the development and validation of kinetic models. Although experimental methods have advanced over the past few decades (e.g., [1]), there are still uncertainties associated with standard experiments (e.g., [2]) that could have a major effect on kinetics given the relatively low sensitivity of flame properties to rate constants [3]. Minimizing experimental uncertainties requires the in-depth understanding of the controlling physics of the experimental approach as well as rigorous assessment of the assumptions of the hydrodynamic model that is used in the numerical simulations.

Molecular beam mass spectrometry (MBMS) [4] is among the leading techniques in measuring species concentrations in chemically reacting flows. The method mainly comprises probing a lowpressure (40 mbar - 100 mbar) burner-stabilized premixed laminar flame with a conical quartz nozzle at various depths in order to characterize the chemical structure. Having been a staple in combustion chemistry studies for more than fifty years and serving as an invaluable tool in kinetics studies [5], the method nonetheless suffers from an inescapable drawback, namely the potential distortion by the probe of the flame from its one-dimensional adiabatic structure that is assumed in numerical simulations. This issue of probe-induced effects on flames is not limited to the MBMS technique. For instance, gas chromatography measurements are just as prone to these distortions [6]. Efforts in the past [7-9] have focused on quantifying these systematic errors to be able to "subtract" them out. Recently, Struckmeier et al. [10] published the results of a comprehensive experimental investigation on the effects of probe angle, orifice diameter, and other experimental parameters of the flame structure. Skovorodko et al. [11] developed a code to model the entire experimental domain including the expansion section in the nozzle. However, this was done using single-step chemistry and by spatially fixing the source terms in the energy and species conservation equations. 
A systematic and rigorous computational study of probe effects in low-pressure flame sampling that delineates the effects of all the relevant boundary conditions while incorporating detailed chemistry has yet to appear. One possible reason for this is the lack of freely available, open-source numerical codes that could be modified to describe the exact laboratory conditions and used by experimentalists. Recently, Cuoci et al. [12] have advanced the laminarSMOKE finite-volume based code built using the OpenFOAM [13] suite of CFD tools and the OpenSMOKE [14] library of functions that handles detailed chemistry and transport while offering an interface to various ODE solvers. The code also incorporates a robust algorithm for time stepping, making it amenable to the stiff chemistry normally encountered in combustion applications.

The goal of this investigation was to perform for the first time direct numerical simulations of the probe effects on the structure of a low-pressure laminar flame and to assess the deviations from results obtained in unperturbed flames; it should be noted that in direct numerical simulations all pertinent spatial and temporal scales are resolved without any simplifying assumption in any type of flow laminar or turbulent alike. Towards that goal, the laminarSMOKE [13] code was adopted to conditions that are close to the experimental ones. The simulations are considered as direct given that the fluid mechanics, chemical kinetics, and heat and mass transport processes were modeled based on the current state-ofthe-art knowledge and without invoking any simplifying assumptions. This approach will lay the fundament for further study with the aim to provide correction rules for existing data and result eventually in an optimized probe design that would cause a minimum disturbance to the flame. 


\section{Modeling approach}

Numerical simulations of the three-dimensional problem coupling fluid dynamics and full chemistry in this study are based on the laminarSMOKE code which addresses the stiff chemistry [15] component of reacting flows by employing the Strang splitting [16], a procedure founded on the premise that for suitably small time steps the processes of molecular transport and reaction can be separated into a sequence of time integrations wherein the final solution of the transport step is the initial condition for the reaction step. The reaction step is thus reduced to a spatial array of homogeneous reactors with appropriate initial conditions whose time integration is handled by standard ODE solvers such as DVODE [17] that was used in the present study. The Strang splitting layer is superimposed on the wellestablished PISO algorithm (Pressure Implicit with Splitting of Operators) [18] for the pressure-velocity coupling, to complete the algorithm for solving the discretized conservation equations [19].

The study was performed for a 50 mbar propene/oxygen/argon mixture at an equivalence ratio $\phi=2.3$ with mole fractions $0.255 / 0.495 / 0.25$ respectively, a $\mathrm{C} / \mathrm{O}$ ratio of 0.773 , and a velocity of $48 \mathrm{~cm} / \mathrm{s}$ at the burner exit that is the inlet of the solution domain; matching the experiments in [9]. The USC Mech-II kinetic model [20] was reduced from 117 species to 34 species using the directed relation graph (DRG) method [21] to save computational cost while preserving the essential aspects of the flame structure; the reduced model can be found in Table S1 of the supplementary material along with comparisons of temperature and key species profiles with the detailed model. Thermal radiation and Soret diffusion were not included, and the thermodynamic, transport, and kinetic properties were evaluated using the OpenSMOKE library [14]. The Soret diffusion formulation is not available in the current version of laminarSMOKE. The code will be modified to account for it in subsequent studies in which the aim will be to perform quantitative comparisons against available experimental results. 
The axisymmetric geometry of the solution domain as seen in Fig. 1 was enclosed by the surfaces whose boundary conditions are defined in Table 1 for all cases considered. These cases were chosen in order to isolate the various effects related to geometry, heat loss, and compressibility.

The problem was first solved on a series of coarse grids and subsequently mapped on to grids of increasing cell density. In the last level of refinement, the number of cells in the incompressible cases when the orifice is closed (UP, AFC, NAFC, AC, NAC, defined in Table 1) were approximately 20,000 skewed by a geometric progression to achieve sub-micrometer cell sizes close to the orifice and the reaction zones. For the compressible cases ( $\mathrm{AO}, \mathrm{NAO}$, defined in Table 1) when the orifice is open, approximately 80,000 cells were used to ensure reasonably mesh-independent solutions in which species concentrations changed by less than $1 \%$ upon doubling the number of cells. Interpolation schemes used to evaluate variables at the control volume faces were linear.

Implicit Euler time stepping was used to arrive at the steady-state solution. The geometric algebraic multi-grid (GAMG) solver was used for the pressure Poisson equation (PPE), preconditioned with diagonal incomplete Cholesky factorization (DIC) whereas the compressible cases required the diagonal incomplete LU (DILU) factorization owing to the asymmetry of the coefficient matrix in PPE [22]. For all other variables, the biconjugate gradient (BiCG) method with DILU preconditioning was used. These linear algebra routines [23] and differencing schemes are all part of the OpenFOAM toolbox. All grids were generated using Gmsh [24]. The modified PISO algorithm used in OpenFOAM accompanied by an analysis of the discretization errors can be found in Ref. 25 .

Neumann-type pressure boundary conditions were specified everywhere except at the outlet of the domain in the UP, AFC, AC, NAFC, and NAC cases. The AO and NAO cases were simulated using the Dirichlet-type boundary conditions to achieve transonic flow at the vicinity of the orifice. For high Reynolds number flows, specifying the gradient of pressure, $\nabla \mathrm{p}$, as zero is a justified approximation at the probe and flange owing to boundary layer theory [26]. At the main and co-flow inlets, $\nabla \mathrm{p}$ isn't strictly zero and is proportional to the second spatial derivative of velocity [27], but this coupling was 
neglected in the present study in order to separate out the complexities that arise from such feedback effects.

The inlet boundary condition for species mass fractions was of the Robin type, wherein the convective and diffusive flux contributions are required to add up to the net supply of species specified upstream [28]. The temperature boundary conditions at the probe and flange were of the Dirichlet type, thus asserting the temperature instead of solving for them via Robin boundary conditions that require as input the heat transfer coefficient and an estimate of the amount of heat transferred. This approximation is justified, as among the goals of the present study is to characterize the effect of heat loss from the flame.

\section{Results and discussion}

\subsection{Unperturbed Case (UP)}

This reference case is void of probe and flange effects. The flame is attached to the burner with the $\mathrm{OH}$ profile peaking at around $0.5 \mathrm{~cm}$ from the burner exit. The axial temperature profile of the unperturbed case is slightly lower compared to the solution obtained using the PREMIX code [29], due to radial temperature gradients caused by the cold argon co-flow as shown in Fig. 2. As will be shown in the following cases, the radial variations of species and temperature are highly coupled and perturbations grow in severity in the presence of the probe as evident in Fig. 3, calling into question the standard approach of simulating such flames by solving the species conservation equation for a given measured temperature profile in one dimension.

\subsection{Adiabatic Flange Only; Closed Orifice Case (AFC)}

In the experiments, the probe and flange are moved towards and away from the flame as one unit. To isolate the various effects, first simulations were carried out with an adiabatic flange only present at 
$6 \mathrm{~cm}$ and $5.4 \mathrm{~cm}$ from the burner exit. These correspond to orifice locations of $1 \mathrm{~cm}$ (of which all corresponding plots can be found in the supplementary material) and $0.6 \mathrm{~cm}$, when the probe is present. A key difference in the AFC case compared to the UP case is the no-slip boundary condition in the former. For the classic stagnation premixed flame, Egolfopoulos et al. [30] have shown that the no-slip boundary condition decreases the strain rate throughout the flame, thereby increasing the residence time of chemical species and correspondingly the maximum temperature with respect to the UP case. This reasoning equally applies to the current burner-stabilized flames and was confirmed in these simulations as shown in Fig. 4.

This stagnation flow configuration is the underpinning for a large portion of laminar flame studies due to its simple quasi one-dimensional character. Flames studied in this setting are simulated typically via the OPPDIFF code [31]. If the probe were thought to collapse onto the flange while its orifice remains on the central axis, the difficult two-dimensional problem of "probe-induced effects" is reduced to a reasonably accurate one-dimensional problem of "flange-induced effects", thus amenable to modeling via a slightly modified version of OPPDIFF [31], provided the open orifice effects are shown via experiment to be negligible. This novel departure is the basis of the recent burner-stabilized stagnation (BSS) flame approach used to measure soot particle size distributions in premixed flames [32]. The flange-induced perturbations documented by that study agree qualitatively with the present ones.

\subsection{Non-Adiabatic Flange Only; Closed Orifice Case (NAFC)}

As shown in Table 1, the flange temperature is set to $600 \mathrm{~K}$, and as long it is sufficiently far away from the flame, the heat loss does not perturb the flame significantly. The results of Fig. 4 indicate that the maximum temperature slightly increases with respect to the UP case, similar to the BSS flame studies. 


\subsection{Adiabatic Flange and Probe; Closed Orifice Case (AC)}

Superposing an adiabatic probe with a closed orifice on the above configuration decreases the temperature at the sampling location by about $40 \mathrm{~K}$, as shown in Fig. 5. The $\mathrm{OH}$ concentration has not reached its equilibrium value when the orifice is at $1 \mathrm{~cm}$ from the burner exit, as shown in Fig. 6 . Therefore, its consumption via $\mathrm{CO}+\mathrm{OH} \rightarrow \mathrm{CO}_{2}+\mathrm{H}$ decreases due to the decreased residence time caused by the presence of a stagnation surface. However, the low probe cone angle of $20^{\circ}$ mitigates this effect by introducing only a mild change in the direction of the streamlines and hence even when the orifice is located at $0.6 \mathrm{~cm}$ from the burner exit, the perturbation is relatively minor. Greater probe angles are expected to decrease the temperature further because of the increased effective stagnation surface impinged upon by fluid upstream, and when conduction losses are considered the situation could worsen. On the other hand, narrow probe angles cannot be used because in the supersonic expansion section of the MBMS probe, satisfactory freezing of the reactions is achieved only for wider probe angles [7].

\subsection{Non-Adiabatic Flange and Probe; Closed Orifice Case (NAC)}

Relaxing the assumption of adiabaticity, the probe temperature $(1600 \mathrm{~K})$ was chosen to mimic the softening temperature of quartz, which is the maximum possible probe temperature attainable in the actual experiment, thus introducing heat losses and decreasing the reactivity of the flame, especially around the orifice where the temperature is the lowest. This effect is expected to worsen when the orifice is brought closer to the burner exit, or the probe angle is increased as a larger portion of the flame loses heat to the probe.

When the conduction losses to the probe become comparable to the conduction losses to the burner surface, the flame can attach itself to the probe, a phenomenon observed during measurements for large (around $65^{\circ}$ ) probe angles [10]. This tendency to attach to the probe can be seen in the $\mathrm{OH}$ mass 
fraction contours for the perturbed flame in Fig. 3. Many chemical reactions are thus left incomplete or quenched. The local quenching cascades upstream, especially via species with large destruction timescales, perturbing the entire chemical structure of the flame. Consider for example, the consumption of the highly active ketynyl radical (HCCO) that depends on the $\mathrm{HCCO}+\mathrm{H} \rightarrow \mathrm{CH}_{2} *+\mathrm{CO}$ reaction. The temperature drop close to the probe reduces the $\mathrm{H}$ concentration, thereby reducing the rate of consumption of $\mathrm{HCCO}$ and subsequently increasing the concentration of $\mathrm{CO}$. This elevated $\mathrm{CO}$ concentration at the orifice tends to increase the diffusive flux upstream. At the same time, the Robin boundary condition imposed at the burner exit balances any diffusive flux with an equal and opposite convective flux, thus producing an increased $\mathrm{CO}$ mass fraction at the burner exit.

\subsection{Adiabatic Open Orifice Case (AO)}

Before allowing for suction through the orifice for the NAC case, it is worthwhile to observe how the temperature field changes solely due to suction in the absence of conduction losses. The dramatic drop in temperature close to the probe shown in Fig. 5 is due to the rapid conversion of sensible enthalpy to kinetic energy. The first order extent of influence in the temperature field is proportional to the diameter of the orifice unlike the NAC case. The chemical reactions are nearly frozen in this region causing the similar cascade effect mentioned above.

\subsection{Non-Adiabatic Open Orifice Case (NAO)}

This corresponds closely to the realistic case in which conduction losses and suction are simultaneously present. The thickness of the momentum boundary layer in the vicinity of the orifice is decreased due to the increased local velocity. Since the Prandtl number is close to one, the thermal boundary layer is also diminished by roughly the same extent, tending to reduce the overall heat transfer to the probe. 
When the orifice is at $1 \mathrm{~cm}$ from the burner exit, the temperature upstream of the compressible flow region falls more or less between the NAC and the AO cases. Analysis showed that the gas density, $\rho$, at the tip is highest compared to both these cases. This results in a particularly interesting change in the kinetic pathway of the formyl radical $(\mathrm{HCO})$, which is mainly consumed via $\mathrm{HCO}+\mathrm{M} \rightarrow \mathrm{H}+\mathrm{CO}+\mathrm{M}$, whose reverse rate is favored at high densities resulting thus in decreased amounts of $\mathrm{CO}$ and $\mathrm{H}$ near the tip and increased amounts of HCO. Although the same phenomenon is observed when the orifice is $0.6 \mathrm{~cm}$ from the burner exit, the overwhelming effects of increased strain rate and heat loss mentioned above nearly quench the central core of the flame, causing the distorted $\mathrm{OH}$ field seen in Fig. 3.

Such effects have major influences on soot production as well. The propargyl radical $\left(\mathrm{C}_{3} \mathrm{H}_{3}\right)$, a major precursor to soot formation, is notably affected, as seen in Fig. 8. Similar effects were seen for the acetylene $\left(\mathrm{C}_{2} \mathrm{H}_{2}\right)$ and ethylene $\left(\mathrm{C}_{2} \mathrm{H}_{4}\right)$ concentration profiles.

\section{Concluding remarks}

The effects of probe and the supporting flange used in low-pressure flame sampling were investigated through direct numerical simulations and the use of detailed descriptions of chemical kinetics and molecular transport. A rich 50 mbar propene/oxygen/argon flame was modeled using laminarSMOKE, a fully compressible finite-volume open-source code. Given that there is vast variation of scales in this problem resulting from both kinetics and compressibility, notable effort was dedicated to the various numerical algorithms involved as well as towards achieving sufficient spatial resolution and solution convergence. Approximately 20,000 and 80,000 cells were used for the incompressible and compressible cases considered, which correspond to closed and open sampling orifice respectively.

Even under adiabatic conditions, it was determined that the presence of the flange with or without the conical probe has a notable effect on the flame structure that becomes two-dimensional. Introducing 
heat loss and compressibility by allowing for suction through the sampling orifice resulted in further deviations of the flame structure compared to that of a one-dimensional unperturbed flame.

The results of this first study of its kind will guide future investigations towards developing correction rules for existing data and eventually optimizing the probe design in order to minimize flame structure perturbations. 


\section{Acknowledgements}

This material is based upon work supported as part of the CEFRC, an Energy Frontier Research Center funded by the U.S. Department of Energy, Office of Science, and Office of Basic Energy

Sciences under Award Number DE-SC0001198. K. Kohse-Höinghaus was partially supported by the Deutsche Forschungsgemeinschaft under SFB 686, TP B3. 


\section{References}

[1] E. Ranzi, A. Frassoldati, R. Grana, A., T. Faravelli, A.P. Kelley, C.K. Law, Prog. Energy Combust. Sci. 38 (2012) 468-501.

[2] C. Ji, E. Dames, Y.L. Wang, H. Wang, F.N. Egolfopoulos, Combust. Flame 157 (2010) 277-287.

[3] A.T. Holley, X.-Q. You, E. Dames, H. Wang, F.N. Egolfopoulos, Proc. Comb. Inst. 32 (2009) 1157-1163.

[4] J.C. Biordi, C.P. Lazzara, J.F. Papp, Combust. Flame 23 (1974) 73-82.

[5] N. Hansen, T.A. Cool, P.R. Westmoreland, K. Kohse-Höinghaus, Prog. Energy Combust. Sci., Volume 35 (2009) 168-191.

[6] E.W. Kaiser, T.J. Wallington, M.D. Hurley, J. Platz, H.J. Curran, W.J. Pitz, C.K. Westbrook, J. Phys. Chem. 104 (2000) 8194-8206.

[7] A.N. Hayhurst, D.B. Kittelson, N.R. Telford, Combust. Flame 28 (1977) 123-135.

[8] A.C. Yi, E.L. Knuth, Combust. Flame 63 (1986) 369-379.

[9] A.T. Hartlieb, B. Atakan, K. Kohse-Höinghaus Combust. Flame 121 (2000) 610-624.

[10] U. Struckmeier, P. Oßwald, T. Kasper, L. Böhling, M. Heusing, M. Köhler, A. Brockhinke, K. Kohse-Höinghaus Z. Phys. Chem. 223 (2009) 503-537.

[11] P.A. Skovorodko, A.G. Tereshchenko, O.P. Korobeinichev, D.A. Knyazkov, A.G. Shmakov, Combust. Theory Model. 17 (2013) 1-24.

[12] A. Cuoci, A. Frassoldati, T. Faravelli, E. Ranzi, Combust. Flame 160 (2013) 870-886.

[13] OpenFOAM, www.openfoam.org, 2013.

[14] A. Cuoci, A. Frassoldati, T. Faravelli, E. Ranzi, OpenSMOKE: numerical modeling of reacting systems with detailed kinetic mechanisms, in: XXXIV Meeting of the Italian Section of the Combustion Institute, Rome, Italy, 2011.

[15] R.J. Kee, M.E. Coltrin, P. Glarborg, Chemically reacting flow: theory and practice, WileyInterscience. (2005).

[16] G. Strang, SIAM Journal on Numerical Analysis 5 (1968), 506-517

[17] P.N. Brown, G.D. Byrne, A.C. Hindmarsh, SIAM journal on scientific and statistical computing 10(5) (1989), 1038-1051.

[18] R.I. Issa, Journal of Computational Physics, 62 (1986) 40-65.

[19] J.H. Ferziger, M. Perić, Computational methods for fluid dynamics, Chapter 5, Berlin: Springer, 1996.

[20] H. Wang, X.-Q. You, A.V. Joshi, S.G. Davis, A. Laskin, F.N. Egolfopoulos, C.K. Law, USC Mech Version II. High-Temperature Combustion Reaction Model of $\mathrm{H}_{2} / \mathrm{CO} / \mathrm{C}_{1}-\mathrm{C}_{4}$ Compounds. http://ignis.usc.edu/USC_Mech_II.htm, May 2007.

[21] T. Lu, C.K. Law, Proc. Combust. Inst. 30 (2005) 1333-1341.

[22] I. Demirdžić, Z. Lilek, and M. Perić, Int. J. Numer. Meth. Fluids 16 (1993) 1029-1050. 
[23] Y. Saad, Iterative methods for sparse linear systems, SIAM (2003).

[24] C. Geuzaine, J. F. Remacle, Int. J. Numer. Meth. Eng. 79 (2009) 1309-1331.

[25] H. Jasak, Error analysis and estimation for the finite volume method with applications to fluid flows, Doctoral dissertation, Imperial College London (1996).

[26] H. Schlichting, Boundary-layer theory, New York: McGraw-Hill (1968).

[27] P.M. Gresho, and R.L. Sani, Int. J. Numer. Meth. Fluids 7 (1987) 1111-1145.

[28] M.D. Smooke, J. Comput. Phys. 48 (1982) 72-105.

[29] R.J. Kee, J.F. Grcar, M.D. Smooke, J.A. Miller, PREMIX: A Fortran program for modeling steady laminar one-dimensional premixed flames, Sandia National Laboratories Report 1985.

[30] F.N. Egolfopoulos, H. Zhang, Z. Zhang, Combust. Flame 109 (1997) 237-252.

[31] R.J. Kee, J.A. Miller, G.H. Evans, G. Dixon-Lewis, Proc. Comb. Inst. 22 (1988) 1479-1494.

[32] A.D. Abid, J. Camacho, D.A. Sheen, H. Wang, Combust. Flame 156 (2009) 1862-1870. 


\section{Table and Figure captions:}

Table 1. Boundary conditions employed for all cases considered. " $\mathrm{e}_{\mathrm{k}}$ " is the flux fraction of the species specified upstream of the burner exit. The velocity normal to the surface is denoted by $U_{n}$.

Figure 1. Schematic of the axisymmetric computational domain. The orifice is placed at a constant perpendicular distance of $5 \mathrm{~cm}$ from the flange so that the domain height is $6 \mathrm{~cm}$ when the orifice is at $1 \mathrm{~cm}$ from the burner exit and $5.4 \mathrm{~cm}$ when the orifice is at $0.6 \mathrm{~cm}$ from the burner exit.

Figure 2. Streamlines superimposed on temperature contours for the unperturbed case (left) compared to a perturbed case (right) with heat loss to the probe and flange along with suction through the orifice.

Figure 3. $\mathrm{OH}$ mass fraction contours for the unperturbed case (left) compared to a perturbed case (right) with heat loss to the probe and flange and suction through the orifice.

Figure 4. Centerline temperature profiles when the flange (in the absence of the probe) is placed at $6 \mathrm{~cm}$ (left) and $5.4 \mathrm{~cm}$ (right) from the burner exit.

Figure 5. Centerline temperature profile when the orifice is at $0.6 \mathrm{~cm}$ from the burner exit.

Figure 6. Centerline $\mathrm{OH}$ mass fraction profile when the orifice is at $0.6 \mathrm{~cm}$ from the burner exit.

Figure 7. Centerline HCO mass fraction profile when the orifice is at $0.6 \mathrm{~cm}$ from the burner exit.

Figure 8. Centerline $\mathrm{C}_{3} \mathrm{H}_{3}$ mass fraction profile when the orifice is at $0.6 \mathrm{~cm}$ from the burner exit. 


\begin{tabular}{|c|c|c|c|c|c|c|}
\hline Cases & Orifice & Probe & Flange & Burner Exit/ Inlet & Co-flow & Outlet \\
\hline Unperturbed (UP) & N/A & N/A & N/A & $\begin{array}{l}\nabla \mathrm{p}=0 \\
\mathrm{~T}=303 \mathrm{~K} \\
\mathrm{Y}_{\mathrm{k}}+\left(\mathrm{D}_{\mathrm{k}} / \mathrm{U}\right) \nabla \mathrm{Y}_{\mathrm{k}}=\mathrm{e}_{\mathrm{k}} \\
\mathrm{U}_{\mathrm{n}}=48 \mathrm{~cm} / \mathrm{s}\end{array}$ & $\begin{array}{l}\nabla \mathrm{p}=0 \\
\mathrm{~T}=303 \mathrm{~K} \\
\mathrm{Y}_{\mathrm{AR}}=1.0 \\
\mathrm{U}_{\mathrm{n}}=48 \mathrm{~cm} / \mathrm{s}\end{array}$ & $\begin{array}{l}\mathrm{p}=50 \mathrm{mbar} \\
\nabla \mathrm{T}=0 \\
\nabla \mathrm{Y}_{\mathrm{k}}=0 \\
\nabla \mathbf{U}=0\end{array}$ \\
\hline $\begin{array}{l}\text { Adiabatic Flange } \\
\text { only; Closed } \\
\text { Orifice (AFC) }\end{array}$ & $\mathrm{N} / \mathrm{A}$ & N/A & $\begin{array}{l}\nabla \mathrm{p}=0 \\
\nabla \mathrm{T}=0 \\
\nabla \mathrm{Y}_{\mathrm{k}}=0 \\
\mathrm{U}_{\mathrm{n}}=0\end{array}$ & $\begin{array}{l}\nabla \mathrm{p}=0 \\
\mathrm{~T}=303 \mathrm{~K} \\
\mathrm{Y}_{\mathrm{k}}+\left(\mathrm{D}_{\mathrm{k}} / \mathrm{U}\right) \nabla \mathrm{Y}_{\mathrm{k}}=\mathrm{e}_{\mathrm{k}} \\
\mathrm{U}_{\mathrm{n}}=48 \mathrm{~cm} / \mathrm{s}\end{array}$ & $\begin{array}{l}\nabla \mathrm{p}=0 \\
\mathrm{~T}=303 \mathrm{~K} \\
\mathrm{Y}_{\mathrm{AR}}=1.0 \\
\mathrm{U}_{\mathrm{n}}=48 \mathrm{~cm} / \mathrm{s}\end{array}$ & $\begin{array}{l}\mathrm{p}=50 \mathrm{mbar} \\
\nabla \mathrm{T}=0 \\
\nabla \mathrm{Y}_{\mathrm{k}}=0 \\
\nabla \mathbf{U}=0\end{array}$ \\
\hline $\begin{array}{l}\text { Non-Adiabatic } \\
\text { Flange only; } \\
\text { Closed Orifice } \\
\text { (NAFC) } \\
\end{array}$ & N/A & N/A & $\begin{array}{l}\nabla \mathrm{p}=0 \\
\mathrm{~T}=600 \mathrm{~K} \\
\nabla \mathrm{Y}_{\mathrm{k}}=0 \\
\mathrm{U}_{\mathrm{n}}=0\end{array}$ & $\begin{array}{l}\nabla \mathrm{p}=0 \\
\mathrm{~T}=303 \mathrm{~K} \\
\mathrm{Y}_{\mathrm{k}}+\left(\mathrm{D}_{\mathrm{k}} / \mathrm{U}\right) \nabla \mathrm{Y}_{\mathrm{k}}=\mathrm{e}_{\mathrm{k}} \\
\mathrm{U}_{\mathrm{n}}=48 \mathrm{~cm} / \mathrm{s}\end{array}$ & $\begin{array}{l}\nabla \mathrm{p}=0 \\
\mathrm{~T}=303 \mathrm{~K} \\
\mathrm{Y}_{\mathrm{AR}}=1.0 \\
\mathrm{U}_{\mathrm{n}}=48 \mathrm{~cm} / \mathrm{s}\end{array}$ & $\begin{array}{l}\mathrm{p}=50 \mathrm{mbar} \\
\nabla \mathrm{T}=0 \\
\nabla \mathrm{Y}_{\mathrm{k}}=0 \\
\nabla \mathbf{U}=0\end{array}$ \\
\hline $\begin{array}{l}\text { Adiabatic Flange } \\
\text { and Probe; Closed } \\
\text { Orifice (AC) }\end{array}$ & $\begin{array}{l}\nabla \mathrm{p}=0 \\
\nabla \mathrm{T}=0 \\
\nabla \mathrm{Y}_{\mathrm{k}}=0 \\
\mathrm{U}_{\mathrm{n}}=0 \\
\end{array}$ & $\begin{array}{l}\nabla \mathrm{p}=0 \\
\nabla \mathrm{T}=0 \\
\nabla \mathrm{Y}_{\mathrm{k}}=0 \\
\mathrm{U}_{\mathrm{n}}=0\end{array}$ & $\begin{array}{l}\nabla \mathrm{p}=0 \\
\nabla \mathrm{T}=0 \\
\nabla \mathrm{Y}_{\mathrm{k}}=0 \\
\mathrm{U}_{\mathrm{n}}=0\end{array}$ & $\begin{array}{l}\nabla \mathrm{p}=0 \\
\mathrm{~T}=303 \mathrm{~K} \\
\mathrm{Y}_{\mathrm{k}}+\left(\mathrm{D}_{\mathrm{k}} / \mathrm{U}\right) \nabla \mathrm{Y}_{\mathrm{k}}=\mathrm{e}_{\mathrm{k}} \\
\mathrm{U}_{\mathrm{n}}=48 \mathrm{~cm} / \mathrm{s}\end{array}$ & $\begin{array}{l}\nabla \mathrm{p}=0 \\
\mathrm{~T}=303 \mathrm{~K} \\
\mathrm{Y}_{\mathrm{AR}}=1.0 \\
\mathrm{U}_{\mathrm{n}}=48 \mathrm{~cm} / \mathrm{s}\end{array}$ & $\begin{array}{l}\mathrm{p}=50 \mathrm{mbar} \\
\nabla \mathrm{T}=0 \\
\nabla \mathrm{Y}_{\mathrm{k}}=0 \\
\nabla \mathbf{U}=0\end{array}$ \\
\hline $\begin{array}{l}\text { Non-Adiabatic } \\
\text { Flange and Probe; } \\
\text { Closed Orifice } \\
\text { (NAC) }\end{array}$ & $\begin{array}{l}\nabla \mathrm{p}=0 \\
\nabla \mathrm{T}=0 \\
\nabla \mathrm{Y}_{\mathrm{k}}=0 \\
\mathrm{U}_{\mathrm{n}}=0\end{array}$ & $\begin{array}{l}\nabla \mathrm{p}=0 \\
\mathrm{~T}=1600 \mathrm{~K} \\
\nabla \mathrm{Y}_{\mathrm{k}}=0 \\
\mathrm{U}_{\mathrm{n}}=0\end{array}$ & $\begin{array}{l}\nabla \mathrm{p}=0 \\
\mathrm{~T}=600 \mathrm{~K} \\
\nabla \mathrm{Y}_{\mathrm{k}}=0 \\
\mathrm{U}_{\mathrm{n}}=0\end{array}$ & $\begin{array}{l}\nabla \mathrm{p}=0 \\
\mathrm{~T}=303 \mathrm{~K} \\
\mathrm{Y}_{\mathrm{k}}+\left(\mathrm{D}_{\mathrm{k}} / \mathrm{U}\right) \nabla \mathrm{Y}_{\mathrm{k}}=\mathrm{e}_{\mathrm{k}} \\
\mathrm{U}_{\mathrm{n}}=48 \mathrm{~cm} / \mathrm{s}\end{array}$ & $\begin{array}{l}\nabla \mathrm{p}=0 \\
\mathrm{~T}=303 \mathrm{~K} \\
\mathrm{Y}_{\mathrm{AR}}=1.0 \\
\mathrm{U}_{\mathrm{n}}=48 \mathrm{~cm} / \mathrm{s}\end{array}$ & $\begin{array}{l}\mathrm{p}=50 \mathrm{mbar} \\
\nabla \mathrm{T}=0 \\
\nabla \mathrm{Y}_{\mathrm{k}}=0 \\
\nabla \mathrm{U}=0\end{array}$ \\
\hline $\begin{array}{l}\text { Adiabatic Flange } \\
\text { and Probe; Open } \\
\text { Orifice } \\
(\mathrm{AO})\end{array}$ & $\begin{array}{l}\mathrm{p}=20 \mathrm{mbar} \\
\nabla \mathrm{T}=0 \\
\nabla \mathrm{Y}_{\mathrm{k}}=0 \\
\nabla \mathbf{U}=0\end{array}$ & $\begin{array}{l}\nabla \mathrm{p}=0 \\
\nabla \mathrm{T}=0 \\
\nabla \mathrm{Y}_{\mathrm{k}}=0 \\
\mathrm{U}_{\mathrm{n}}=0\end{array}$ & $\begin{array}{l}\nabla \mathrm{p}=0 \\
\nabla \mathrm{T}=0 \\
\nabla \mathrm{Y}_{\mathrm{k}}=0 \\
\mathrm{U}_{\mathrm{n}}=0\end{array}$ & $\begin{array}{l}\nabla \mathrm{p}=0 \\
\mathrm{~T}=303 \mathrm{~K} \\
\mathrm{Y}_{\mathrm{k}}+\left(\mathrm{D}_{\mathrm{k}} / \mathrm{U}\right) \nabla \mathrm{Y}_{\mathrm{k}}=\mathrm{e}_{\mathrm{k}} \\
\mathrm{U}_{\mathrm{n}}=48 \mathrm{~cm} / \mathrm{s}\end{array}$ & $\begin{array}{l}\nabla \mathrm{p}=0 \\
\mathrm{~T}=303 \mathrm{~K} \\
\mathrm{Y}_{\mathrm{AR}}=1.0 \\
\mathrm{U}_{\mathrm{n}}=48 \mathrm{~cm} / \mathrm{s}\end{array}$ & $\begin{array}{l}\mathrm{p}=50 \mathrm{mbar} \\
\nabla \mathrm{T}=0 \\
\nabla \mathrm{Y}_{\mathrm{k}}=0 \\
\nabla \mathbf{U}=0\end{array}$ \\
\hline $\begin{array}{l}\text { Non-Adiabatic } \\
\text { Flange and Probe; } \\
\text { Open Orifice } \\
\text { (NAO) }\end{array}$ & $\begin{array}{l}\mathrm{p}=20 \mathrm{mbar} \\
\nabla \mathrm{T}=0 \\
\nabla \mathrm{Y}_{\mathrm{k}}=0 \\
\nabla \mathbf{U}=0\end{array}$ & $\begin{array}{l}\nabla \mathrm{p}=0 \\
\mathrm{~T}=1600 \mathrm{~K} \\
\nabla \mathrm{Y}_{\mathrm{k}}=0 \\
\mathrm{U}_{\mathrm{n}}=0\end{array}$ & $\begin{array}{l}\nabla \mathrm{p}=0 \\
\mathrm{~T}=600 \mathrm{~K} \\
\nabla \mathrm{Y}_{\mathrm{k}}=0 \\
\mathrm{U}_{\mathrm{n}}=0\end{array}$ & $\begin{array}{l}\nabla \mathrm{p}=0 \\
\mathrm{~T}=303 \mathrm{~K} \\
\mathrm{Y}_{\mathrm{k}}+\left(\mathrm{D}_{\mathrm{k}} / \mathrm{U}\right) \nabla \mathrm{Y}_{\mathrm{k}}=\mathrm{e}_{\mathrm{k}} \\
\mathrm{U}_{\mathrm{n}}=48 \mathrm{~cm} / \mathrm{s}\end{array}$ & $\begin{array}{l}\nabla \mathrm{p}=0 \\
\mathrm{~T}=303 \mathrm{~K} \\
\mathrm{Y}_{\mathrm{AR}}=1.0 \\
\mathrm{U}_{\mathrm{n}}=48 \mathrm{~cm} / \mathrm{s}\end{array}$ & $\begin{array}{l}\mathrm{p}=50 \mathrm{mbar} \\
\nabla \mathrm{T}=0 \\
\nabla \mathrm{Y}_{\mathrm{k}}=0 \\
\nabla \mathbf{U}=0\end{array}$ \\
\hline
\end{tabular}

Table 1. Boundary conditions employed for all cases considered. " $\mathrm{e}_{\mathrm{k}}$ " is the flux fraction of the species specified upstream of the burner exit. The velocity normal to the surface is denoted by $U_{n}$. 


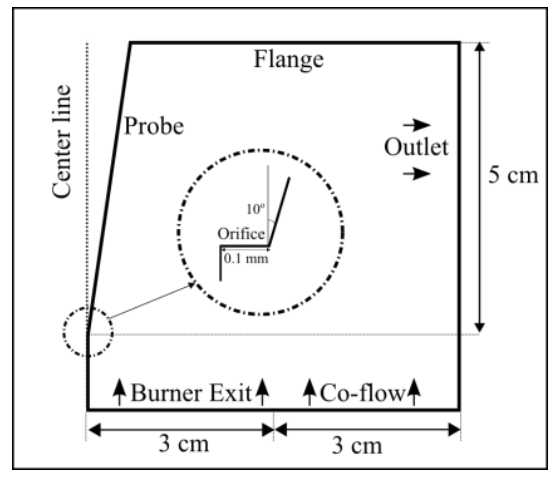

Figure 1. Schematic of the axisymmetric computational domain. The orifice is placed at a constant perpendicular distance of $5 \mathrm{~cm}$ from the flange so that the domain height is $6 \mathrm{~cm}$ when the orifice is at $1 \mathrm{~cm}$ from the burner exit and $5.4 \mathrm{~cm}$ when the orifice is at $0.6 \mathrm{~cm}$ from the burner exit.

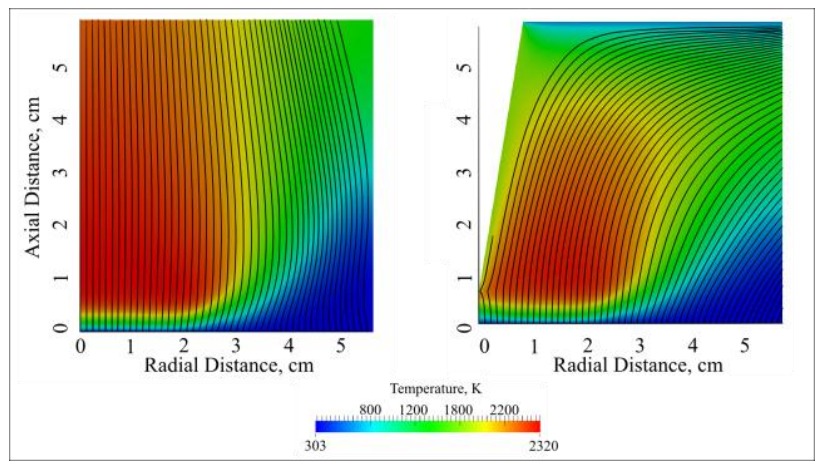

Figure 2. Streamlines superimposed on temperature contours for the unperturbed case (left) compared to a perturbed case (right) with heat loss to the probe and flange along with suction through the orifice. 


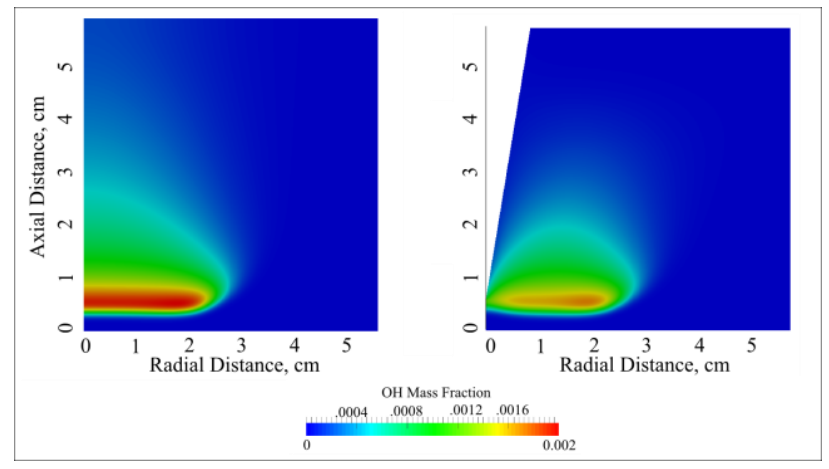

Figure 3. $\mathrm{OH}$ mass fraction contours for the unperturbed case (left) compared to a perturbed case (right) with heat loss to the probe and flange and suction through the orifice.
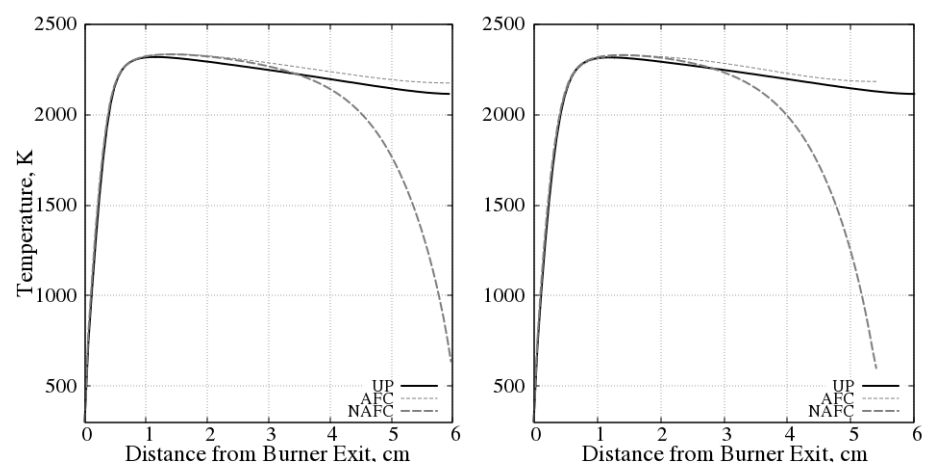

Figure 4. Centerline temperature profiles when the flange (in the absence of the probe) is placed at $6 \mathrm{~cm}$ (left) and $5.4 \mathrm{~cm}$ (right) from the burner exit. 


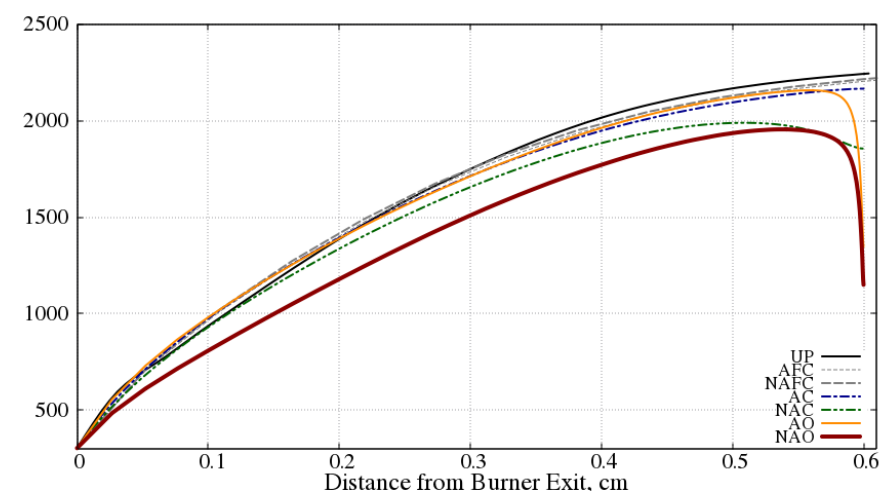

Figure 5. Centerline temperature profile when the orifice is at $0.6 \mathrm{~cm}$ from the burner exit.

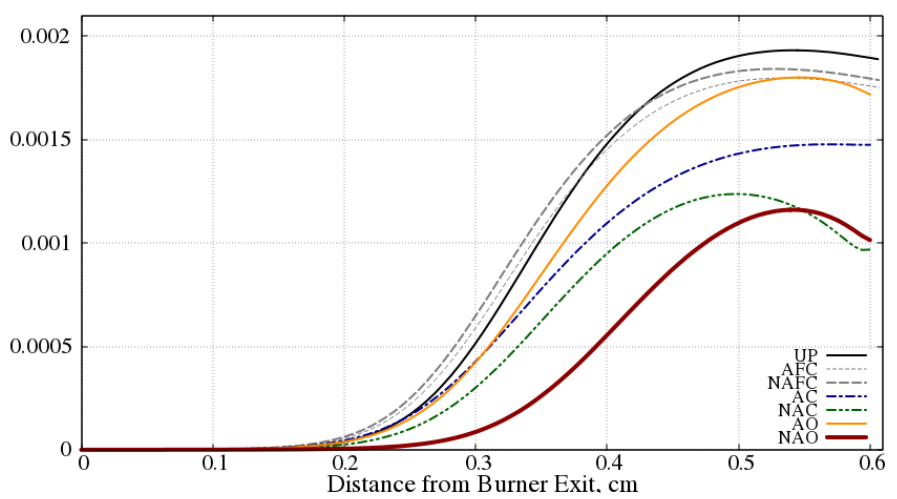

Figure 6. Centerline $\mathrm{OH}$ mass fraction profile when the orifice is at $0.6 \mathrm{~cm}$ from the burner exit.

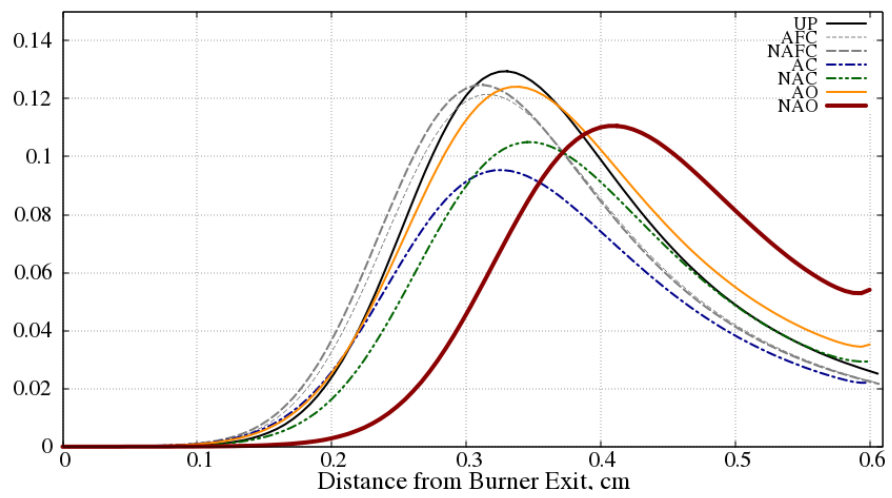

Figure 7. Centerline HCO mass fraction profile when the orifice is at $0.6 \mathrm{~cm}$ from the burner exit. 


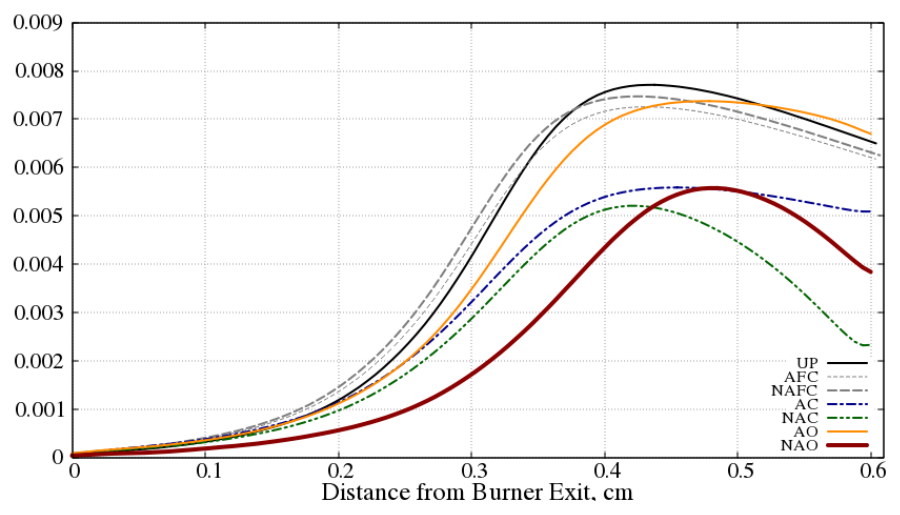

Figure 8. Centerline $\mathrm{C}_{3} \mathrm{H}_{3}$ mass fraction profile when the orifice is at $0.6 \mathrm{~cm}$ from the burner exit.

Supplemental material included with this manuscript:

"Kinetic_Model_TableS1.pdf"

"Supplementary_Figures.pdf" 